\title{
Biodegradation of Gelatin-g-Poly(methyl Acrylate) *
}

Considerable interest has been focused on the synthesis of biodegradable polymers in specialized applications such as controlled release drug formulations, insecticide and pesticide carriers, and nontoxic surgical implant materials. For many agricultural and ecological uses it is desirable to have a biodegradable polymer that will degrade in a physiological environment or by microbial action in the soil.

Natural polymers like carbohydrates and proteins, although biodegradable, cannot be fabricated easily because they decompose before they melt. On the other hand, the literature leads us to conclude that almost all synthetic polymers are resistant to enzymatic attack. ${ }^{1}$ To overcome this apparent paradox among existing polymers several synthetic approaches were formulated ${ }^{2,3}$ to enhance the biodegradabilities of polymers by physical or chemical modification of existing materials or by the development of new ones. In one potential approach graft copolymers are synthesized with a biodegradable backbone (e.g., carbohydrate or proteinaceous materials). Although several reports on the synthesis of graft copolymers with protein backbones have been made, there is none on the biodegradation of these polymers. In this article preliminary studies of the degradation behavior of gelatin-g-PMA are discussed.

\section{EXPERIMENTAL}

Gelatin, bacteriological (BDH), was used in this investigation. Monomer methyl acrylate (BDH) was washed free of inhibitor with a $5 \%$ solution of $\mathrm{NaOH}$, then with water, and finally distilled under nitrogen. The initiator used was $\mathrm{K}_{2} \mathrm{~S}_{2} \mathrm{O}_{8}$ (E. Merck) and solvents were pure AR grade samples, used as such.

\section{Preparation of Gelatin-g-Poly(methyl Acrylate)}

For the preparation of the copolymer an experimental procedure, similar to that of Santappa et al., ${ }^{4}$ was used. Gelatin $(30 \mathrm{~g})$ was added to $300 \mathrm{ml}$ of water and heated to $40^{\circ} \mathrm{C}$ under nitrogen. Distilled methyl acrylate $(35 \mathrm{ml})$ was added to the slurry. Grafting sites were initiated by adding $\mathrm{K}_{2} \mathrm{~S}_{2} \mathrm{O}_{8}(1.62 \mathrm{~g})$. The initiator was divided into four equal portions of $0.405 \mathrm{~g}$, each of which was added at 5 -min intervals. The mixture was allowed to react for $1 \mathrm{hr}$ after the final addition. The product was collected by filtration, washed several times with hot water to remove the residual free gelatin, and dried in air. The sample contained $10 \%$ homopolymer, determined by extraction with toluene. Grafted side chains were removed from the protein backbone by a procedure introduced by Rao et al. ${ }^{5}$ The sample selected for the present study consisted of $50 \%$ poly(methyl acrylate) by weight. The molecular weight found by viscosity measurements in benzene at $30^{\circ} \mathrm{C}$ was 50,000 $\left(\bar{M}_{v}\right)$.

\section{Film Preparation}

The dry polymer was hot pressed into a film of $0.5-\mathrm{mm}$ thickness by a compression molding technique. The die was maintained at $50^{\circ} \mathrm{C}$ at a pressure of $300 \mathrm{~kg} / \mathrm{cm}^{2}$. The film was cut into dumbbell-shaped tensile pieces $(4 \mathrm{~mm} \times 8 \mathrm{~cm})$ and tensile strength and percentage of elongation were measured. The percentage of elongation at break point is 450 ; the ultimate tensile strength, $12.12 \mathrm{MN} / \mathrm{m}^{2}$. The polymer seems to have acceptable physical properties for a variety of applications.

\section{Microbiological Testing}

In the present investigation a single-culture method used bacterial strains like Pseudomonas aeruginosa, Bacillus subtilis, and Serratia marcescens as test organisms known to exhibit high proteolytic activity. For biodegradability testing a mineral salts medium, with the polymer in

* Presented at the International Symposium on "New Frontiers in Polymer Science and Polymer Applications" held at Central Leather Research Institute, Madras, India, January 7-11, 1980. 
question as the sole source of carbon, was used. The composition of the culture medium was as follows: $\mathrm{KH}_{2} \mathrm{PO}_{4}, 0.7 \mathrm{~g} ; \mathrm{K}_{2} \mathrm{HPO}_{4}, 0.7 \mathrm{~g} ; \mathrm{MgSO}_{4} \cdot 7 \mathrm{H} 20,0.7 \mathrm{~g} ; \mathrm{NH}_{4} \mathrm{NO}_{3}, 1.0 \mathrm{~g} ; \mathrm{NaCl}, 0.005 \mathrm{~g} ; \mathrm{FeSO}_{4}$, $0.002 \mathrm{~g} ; \mathrm{ZnSO}_{4}, 0.002 \mathrm{~g}$; and $\mathrm{MnSO}_{4}, 0.001 \mathrm{~g}$ in 1 liter of distilled water. In each tube $0.3 \mathrm{~g}$ of the sample was taken with $10 \mathrm{ml}$ of the mineral salts medium. The tubes were autoclaved at $121^{\circ} \mathrm{C}$ for $20 \mathrm{~min}$. All the bacterial cultures were maintained according to the ASTM standard procedure ${ }^{6}$ Tubes were inoculated with $0.1-\mathrm{ml}$ suspension of the organisms under sterile conditions. The OD of the culture suspension was 0.45 in each case. All the tubes were incubated at $30^{\circ} \mathrm{C}$ for five weeks on a rotating shaker. Good growth was observed in all three sets of tubes inoculated with the organisms.

\section{Weight Loss Measurements}

Visual observations of the extent of bacterial and fungal growth are unreliable and at best only of supplementary value. Characteristics such as flexibility, elasticity, or tensile strength of the sample, in some cases reliably indicate the degree of biodeterioration of the plastic formulation. A single measurement, however, which correlates most closely with all other indices of polymer degradation by microorganisms is weight loss. ${ }^{7}$

In our experiments three tubes were removed every week after inoculation with each organism and submerged in a $0.1 \%$ solution of $\mathrm{HgCl}_{2}$ for $10 \mathrm{~min}$ to halt further action. The samples were thoroughly rinsed with water, blotted dry, and placed in a dessicator for $36 \mathrm{hr}$. They were then weighed and the weight loss was recorded. Results of the correction of the amount of loss in the control samples are given in Figure 1. To ensure that estimates of behavior are not too optimistic, the greatest degree of deterioration is reported according to convention. ${ }^{7}$

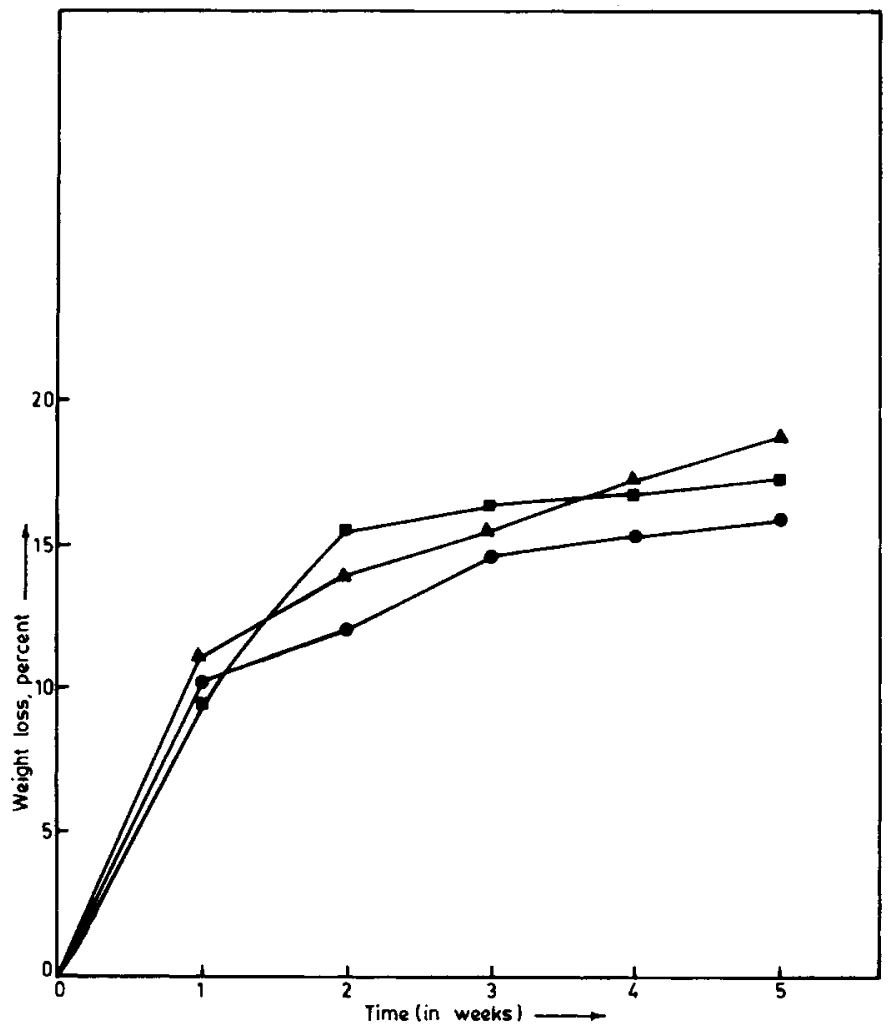

Fig. 1. Weight loss of gelatin-g-poly(methyl acrylate) incubated with (๑) Pseudomononas

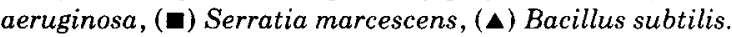


TABLE I

Total Nitrogen Content of the Samples Before and After Testing ${ }^{\mathrm{a}}$

\begin{tabular}{lcc}
\hline Names & $\begin{array}{c}\text { Percentage } \\
\text { of nitrogen } \\
\text { (initial) }\end{array}$ & $\begin{array}{c}\text { Percentage } \\
\text { of nitrogen } \\
\text { (after five weeks) }\end{array}$ \\
\hline Bacillis subtilis & 7.2 & 3.4 \\
Serratia marcescens & 7.2 & 3.8 \\
Pseudomonas aeruginosa & 7.2 & 4.0 \\
\hline
\end{tabular}

a Incubated with Bacillus subtilis, Serratia marcescens, and Pseudomonas aeruginosa

\title{
RESULTS AND DISCUSSION
}

The percentage of weight loss of polymer versus time plots are shown in Figure 1. In the controls the reduction in weight was negligible and data have been corrected for this loss. It can be seen that a 15-18\% loss in weight is caused by different organisms over a period of five weeks. In all cases an initial rapid loss during the first week was followed by a slower and steadier disappearance of the substrate.

The losses in nitrogen content of the samples inoculated with Bacillus, Pseudomonas, and Serratia are listed in Table I. An approximate 45\% drop in nitrogen content of the polymer in each case occurred after five weeks of inocubation, thus indicating the use of the gelatin in the molecule.

The accumulation of free amino acids due to initial rapid hydrolysis might have inhibited further proteolysis. It is also known that the limitation of ammonia in the medium depresses proteolytic enzyme action, ${ }^{8}$ which may explain the retardation in enzymatic hydrolysis after the first week. Bacillus sp. is slightly more effective than the other two, although the difference may not be significant. Further work on the susceptibility of materials of different composition and with different polymers grafted onto the gelatin backbone is in progress.

\section{References}

1. J. E. Potts, in Aspects of Degradation and Stabilization of Polymers, H. H. J. Jellinek, Ed., Elsevier, New York, 1978, p. 617.

2. L. Taylor, Chem. Technol., 542 (September 1979).

3. F. Rodriguez, Chem. Technol., 409 (1971).

4. T. Nagabhushanam, K. T. Joseph, and M. Santappa, J. Polym. Sci. Polym. Chem. Ed., 16, 3292 (1978).

5. K. P. Rao, K. T. Joseph, and Y. Nayudamma, Leather Sci. Madras., 16, 401 (1969).

6. Annual book of ASTM Standards, Part 26, ASTM-D-2676, p. 758 (1970).

7. W. Hazeu, Inst. Biodetn. Bull., 3, 15-19 (1967).

8. D. C. Wang et al., Fermentation and Enzyme Technology, Wiley, New York, 1979.

\author{
G. Sudesh Kumar \\ V. KaLPAGAM \\ U. S. NANDI
}

Department of Inorganic and Physical Chemistry

Indian Institute of Science

Bangalore-560 012, India

V. N. VASANTHARAJAN

Microbiology and Cell Biology Laboratory

Indian Institute of Science

Bangalore-560 012, India

Received September 11, 1980

Revised November 13, 1980

Accepted November 13, 1980 